SOUZA, Greyce Kelly Antunes de. A importância do Princípio da Informação: a necessidade de consciência social acerca dos problemas ambientais para maior proteção ambiental. Revista Eletrônica Direito e Política, Programa de Pós-Graduação Stricto Sensu em Ciência Jurídica da UNIVALI, Itajaí, v.10, n.2, $1^{\circ}$ quadrimestre de 2015. Disponível em: www.univali.br/direitoepolitica - ISSN 1980-7791.

\title{
A IMPORTÂNCIA DO PRINCÍPIO DA INFORMAÇÃO: A NECESSIDADE DE CONSCIÊNCIA SOCIAL ACERCA DOS PROBLEMAS AMBIENTAIS PARA MAIOR PROTEÇÃO AMBIENTAL
}

\author{
LA IMPORTANCIA DEL PRINCIPIO DE LA INFORMACIÓN: LA NECESIDAD DE \\ UMA CONSCIÊNCIA SOCIAL SOBRE LOS PROBLEMAS AMBIENTALES MAYOR \\ PROTECCIÓN DEL MÉDIO AMBIENTE
}

Greyce Kelly Antunes de Souza ${ }^{1}$

SUMÁRIO: Introdução; 1 . Princípio e Regras: semelhanças e diferenças; 1.1 Princípios e sua importância no ordenamento jurídico; 2. Princípio da Informação; 2.1 Conceito; 2.2 Breve previsão histórica do Princípio da Informação no contexto ambiental; 3. Princípio da Informação e sua função ao meio ambiente; Considerações Finais; Referências das Fontes Citadas.

RESUMO: As normas jurídicas se dividem em normas princípios e normas regras. Os princípios são mais amplos e abstratos que as regras, tornando esta mais específica em relação a ele. Outra particularidade que distingue princípio de regra é que, para o princípio ser aplicado, e por ser mais amplo e abstrato, é necessário que haja uma ponderação por parte do aplicador durante a análise do caso concreto, já a regra não precisa de mediação, pois se encontra pronta para ser aplicada. O princípio é passível de reflexão, já a regra não. Para ser aplicado o princípio precisa ser analisado, já a regra não possui esse meio termo, ou é aplicada no caso concreto ou não é. Então, para concluir essa distinção, o princípio é caracterizado por ser fundamentador, integrador, explicador, já a regra apresenta caráter proibitivo ou permissivo. Por esta prever determinada conduta, apresenta um exercício mais rígido que o princípio. Tratando de princípios, tendo em vista o enfoque do presente artigo, sua função é fundamentar para a formação das normas de direito, complementar e interpretar o ordenamento jurídico. No que diz respeito ao direito à informação o presente artigo elucida que a informação protege cada pessoa, tendo em vista que ela será base sobre o qual se tomará decisões que afetarão o interesse e

\footnotetext{
${ }^{1}$ Mestranda do Programa de Pós Graduação Stricto Sensu em Ciência Jurídica - PPCJ - UNIVALI. Bolsista no Programa de Suporte à Pós-Graduação de Instituições de Ensino Particulares - PROSUP - CAPES. Graduada em Direito pela Universidade do Vale do Itajaí - UNIVALI.Email: greyce.kelly@univali.br
} 
SOUZA, Greyce Kelly Antunes de. A importância do Princípio da Informação: a necessidade de consciência social acerca dos problemas ambientais para maior proteção ambiental. Revista Eletrônica Direito e Política, Programa de Pós-Graduação Stricto Sensu em Ciência Jurídica da UNIVALI, Itajaí, v.10, n.2, 10 quadrimestre de 2015. Disponível em: www.univali.br/direitoepolitica - ISSN 1980-7791.

necessidade de cada um. Ainda que a informação se torna pública não só porque está em poder do Poder Público, mas em razão de que a natureza representa interesse público, sendo assim a mesma adquire natureza pública, ainda que esteja em mãos de pessoas ou das empresas privadas. E por fim, destaca-se a especial importância do direito à informação quanto ao meio ambiente e seus efeitos positivos, uma vez que quanto maior for o conhecimento acerca das características, das fragilidades, e singularidades do conjunto de bens ambientais existentes, maior será a respectiva da proteção ambiental e, por consequência, da preservação dos recursos naturais.

Palavras-chave: Princípio; Princípio da Informação; Meio Ambiente.

RESUMEN: Las normas jurídicas se dividen en principios y reglas. Los principios son más amplio y abstracto de las normas, por lo que esta más específica acerca de él. Otra característica que distingue a la regla de principio es que el principio que debe aplicarse, y ser más amplio y abstracto, tiene que haber un equilibrio por el aplicador durante el análisis del caso, ya que la norma no necesita la mediación, ya que está listo para ser aplicado. El principio es capaz de reflexión, ya que la norma no lo hace. Para aplicar el principio para ser analizada, ya que la norma no tiene ese punto intermedio, o se aplica en este caso o no. Para concluir esta distinción, el principio se caracteriza por ser fundamentador, integrador, explicador, ya que la norma tiene carácter prohibitivo o permisiva. Para ello proporciona cierta conducta, es el ejercicio más duro ese principio. Dirigiéndose a los principios, dado el enfoque de este artículo, su función es apoyar la formación de normas jurídicas, complementar e interpretar la ley. En cuanto al derecho a la información de este artículo aclara que la información protege a cada persona, teniendo en cuenta que es la base sobre la cual tomar decisiones que afectan a los intereses y necesidades de cada uno. Aunque la información se haga pública, no sólo porque se lleva a cabo por el gobierno, pero debido a que la naturaleza es de interés público, por lo que adquiere un carácter público, a pesar de que está en manos de particulares o empresas privadas. Por último, destaca-se la importancia particular del derecho a la información sobre el medio ambiente y sus efectos positivos, ya que a mayor conocimiento sobre las características, debilidades, y conjunto existente de bienes ambientales de singularidades, mayor será la su protección del medio ambiente y, por lo tanto, la preservación de los recursos naturales.

Palabras clave: Principio; Principio de la Información; Medio Ambiente.

\section{INTRODUÇÃO}

O presente artigo traz como tema principal a importância do princípio da informação para a preservação do Meio Ambiente. O tema é atual e relevante, tendo em vista que a divulgação de informações à população servirá como base 
SOUZA, Greyce Kelly Antunes de. A importância do Princípio da Informação: a necessidade de consciência social acerca dos problemas ambientais para maior proteção ambiental. Revista Eletrônica Direito e Política, Programa de Pós-Graduação Stricto Sensu em Ciência Jurídica da UNIVALI, Itajaí, v.10, n.2, $1^{\circ}$ quadrimestre de 2015. Disponível em: www.univali.br/direitoepolitica - ISSN 1980-7791.

para a opinião pública consciente de suas responsabilidades ambientais e sociais e possíveis influências na qualidade de vida da população.

O seu objetivo é compreender importância que o princípio da informação possui na área do Direito Ambiental e suas consequências ao Meio Ambiente. Tem como objetivo específico, verificar a diferença entre regra e princípio; verificar as funções dos princípios e o surgimento e destacar a relevância do princípio da informação à preservação do meio ambiente.

O estudo, ora apresentado, analisa a problemática acerca da informação como pressuposto necessário para a preservação do meio ambiente, como meio importante para informar a sociedade a respeito dos acontecimentos desenvolvimentistas e suas implicações para o meio ambiente, bem como as possíveis influências na qualidade de vida da população.

Para melhor compreensão do trabalho, a pesquisa se estrutura da seguinte forma:1. Princípios e Regras: semelhanças e diferenças; 1.1 Princípios e sua importância no ordenamento jurídico; 2. Princípio da Informação; 2.1 Conceito; 2.2 Breve previsão histórica no contexto ambiental; 3. Princípio da Informação e sua função no Meio Ambiente. Incialmente, o presente trabalho tem a intenção de diferenciar princípios de regras, tendo em vista ambos serem normas jurídicas, por seguinte analisou-se também o conceito de princípios e sua importância no ordenamento jurídico. No segundo momento ressalta o conceito de informação, e ainda tratará diretamente sobre o princípio da informação, conceito e uma breve previsão histórica no contexto ambiental. Finalmente observou-se que o princípio da informação possuí seu papel do Direito Ambiental, quanta a preservação do meio ambiente, tendo em vista busca pela educação, consciência e participação ambiental.

A metodologia utilizada foi o método indutivo com as técnicas do referente, da revisão bibliográfica, do fichamento e do conceito operacional. 
SOUZA, Greyce Kelly Antunes de. A importância do Princípio da Informação: a necessidade de consciência social acerca dos problemas ambientais para maior proteção ambiental. Revista Eletrônica Direito e Política, Programa de Pós-Graduação Stricto Sensu em Ciência Jurídica da UNIVALI, Itajaí, v.10, n.2, $1^{\circ}$ quadrimestre de 2015. Disponível em: www.univali.br/direitoepolitica - ISSN 1980-7791.

\section{PRINCÍPIO E REGRAS: SEMELHANÇAS E DIFERENÇAS}

O ordenamento jurídico é formado por um conjunto de normas jurídicas, as quais têm como objetivo principal o controle social, a obtenção da ordem e o bem de toda sociedade. Tais normas são constituídas de duas espécies; os princípios e as regras. $^{2}$

José Joaquim Gomes Canotilho ${ }^{3}$ traz algumas propriedades para diferenciar princípios de regras.

a) Grau de abstração: os princípios são normas com um grau de abstracção relativamente elevado; de modo diverso, as regras possuem uma abstracçsão relativamente reduzida;

b) Grau de determinalidade na aplicação do caso concreto: os princípios, por serem vagos e indeterminados, carecem de mediações concretizadoras (do legislador, do juiz), enquanto as regras são susceptíveis de aplicação directa;

c) Carácter de fundamentalidade no sistema das fontes de direito: os princípios são normas de natureza estruturante ou com um papel fundamental no ordenamento jurídico devido à sua posição hierárquica no sistema das fontes (ex: princípios constitucionais) ou à sua importância estruturante dentro do sistema jurídico (ex: princípios do Estado de Direito);

d) Proximidade da ideia de direito: os princípios são "standards" juridicamente vinculados radicados nas exigências de "justiça" (Dworkin) ou na "ideia de direito" (Larenz); as regras podem ser normas vinculadas com um conteúdo meramente funcional;

e) Natureza normogenética: os princípios são fundamentos de regras, isto é, são normas que estão na base ou constituem a ratio e regras jurídicas, desempenhando, por isso, uma função normogenéticafundamentante.

Riccardo Guastini ${ }^{4}$ também estabelece distinções entre as duas espécies de normas.

\footnotetext{
${ }^{2}$ CANOTILHO, J.J. Gomes. Constitucional e teoria da constituição. $7^{\circ}$ ed. Coimbra: Portugual: Almedina, 2003.p.1160.

${ }^{3}$ CANOTILHO, J.J. Gomes. Constitucional e teoria da constituição. $7^{\circ}$ ed. Coimbra: Portugual: Almedina, 2003. p.1160-1161.
} 
SOUZA, Greyce Kelly Antunes de. A importância do Princípio da Informação: a necessidade de consciência social acerca dos problemas ambientais para maior proteção ambiental. Revista Eletrônica Direito e Política, Programa de Pós-Graduação Stricto Sensu em Ciência Jurídica da UNIVALI, Itajaí, v.10, n.2, $1^{\circ}$ quadrimestre de 2015. Disponível em: www.univali.br/direitoepolitica - ISSN 1980-7791.

(1) São as normas considerados pelo legislador, pela doutrina e/ou pela jurisprudência como fundamento de um conjunto de normas, portanto, a questão de se uma norma tem ou não valor de "princípio" não é uma questão de fato, e a resposta é sempre opinável;

(2) Os princípios também diferenciam-se das normas na sua formulação linguística, pois as normas teriam um significado relativamente preciso, enquanto que os princípios possuam um significado elástico e/ou indeterminado, ou seja, os princípios são, habitualmente normas bastante vagas.

(3) Por fim os princípios caracterizam-se pela generalidade, diverso só que ocorre com as outras normas.

Os princípios são normas básicas inquestionáveis. Constituem os mandamentos primários do direito, estão vinculados aquelas valores fundantes da sociedade, que exprimem o que foi eleito justo. ${ }^{5}$ Por outro lado, as regras jurídicas regulam especificamente o comportamento e a conduta social, tratam sobre a forma de agir em determinadas situações especificas. ${ }^{6}$

Seguindo tal premissa, Lôbo dispõe que um dos principais pontos de distinção entre regras e princípios está relacionado ao fato de que estes são mandados de otimização, "que podem ser cumpridos não somente através das possibilidades fáticas, mas também jurídicas, o que ocasionará diferentes graus de concretização", enquanto as regras, por sua vez, são normas cujo cumprimento somente pode ser realizado ou não, contendo determinações no âmbito fático e juridicamente possível.

Desta forma, percebe-se que os princípios são as normas jurídicas de natureza lógica anterior e superior às regras e que servem de base para a criação, aplicação e interpretação do direito. As regras, por sua vez, são normas jurídicas destinadas a das concretização aos princípios.

${ }^{4}$ GUASTINI, Riccardo. Das fontes às normas. Tradução de Edson Bini. São Paulo: Editora QuartierLatin do Brasil, 2005. p. 186-188.

${ }^{5}$ ATALIBA, Geraldo. República e constituição. 2.ed. São Paulo: Melheiros, 2006. p. 6-7.

${ }^{6}$ BARROSO, Luís Roberto. Interpretação e aplicação da constituição. São Paulo: Saraiva, 1996. p. 141. 
SOUZA, Greyce Kelly Antunes de. A importância do Princípio da Informação: a necessidade de consciência social acerca dos problemas ambientais para maior proteção ambiental. Revista Eletrônica Direito e Política, Programa de Pós-Graduação Stricto Sensu em Ciência Jurídica da UNIVALI, Itajaí, v.10, n.2, $1^{\circ}$ quadrimestre de 2015. Disponível em: www.univali.br/direitoepolitica - ISSN 1980-7791.

Sendo assim, nota-se nitidamente a diferença existente entre princípios e regras. Contudo para o propósito do presente tópico, proceder-se-á tratando sobre princípios haja vista sua importância para compreensão do tema.

\subsection{Princípios e sua importância no ordenamento jurídico}

A palavra princípios significa o alicerce, a base ou o fundamento de alguma coisa. Trata-se de um vocabulário de origem latina e tem o sentido de aquilo que se torna primeiro. ${ }^{7}$

Sirvinskas ${ }^{8}$ destaca a importância dos princípios no ordenamento jurídico, assim dispondo:

Os princípios servem para facilitar o estudo e a analise de certos fundamentos estanques do direito. Prestam-se para balizar o procedimento do legislador, do magistrado e do operador do direito (...) Em outras palavras, princípio é o valor fundamental de uma questão jurídica (...) Os princípios, por seu turno, não podem ser aplicados diretamente ao caso em espécie como uma regra jurídica. Deve-se estabelecer uma relação com as normas constitucionais e infraconstitucionais. No entendo, é por meio dos princípios que se estabelecerá o seu conteúdo valorativo.

No mesmo sentido, destaca Canotilho ${ }^{9}$ os princípios desempenham um papel mediato, ao servirem como critério de interpretação e de integração do sistema, e um papel imediato ao serem aplicados diretamente a uma relação jurídica. Para o autor as três funções principais dos princípios são impedir o surgimento de regras que Ihes sejam contrárias, compatibilizara interpretação das regras e dirimir diretamente o caso concreto frente a ausência de outras regras.

\footnotetext{
7 GUASTINI, Riccardo. Das fontes às normas. Tradução de Edson Bini. São Paulo: Editora QuartierLatin do Brasil, 2005. p. 186-189.

8 SIRVINSKAS, Luis Paulo. Manual de direito ambiental. 12. Ed. São Paulo: Saraiva, 2014. p. 138-139.

${ }^{9}$ CANOTILHO, J.J. Gomes. Constitucional e teoria da constituição. $7^{\circ}$ ed. Coimbra: Portugual: Almedina, 2003.p.122.
} 
SOUZA, Greyce Kelly Antunes de. A importância do Princípio da Informação: a necessidade de consciência social acerca dos problemas ambientais para maior proteção ambiental. Revista Eletrônica Direito e Política, Programa de Pós-Graduação Stricto Sensu em Ciência Jurídica da UNIVALI, Itajaí, v.10, n.2, 10 quadrimestre de 2015. Disponível em: www.univali.br/direitoepolitica - ISSN 1980-7791.

Em outras palavras, os princípios exercem uma função especialmente importante frente às outras fontes do direito porque, além de incidir como norma de aplicação do Direito no caso prático, eles também influenciam na produção de demais fontes do Direito. É com base nos princípios que são feitas as leis, a jurisprudência, a doutrina e os tratados e convenções internacionais, já que traduzem os valores essenciais da Ciência Jurídica.

Em caso de colisão de princípios, não há invalidação de um ou dos dois princípios, mas sim juízos de preponderância em relação ao caso analisado, conforme explica Morais da Rosa ${ }^{10}$ :

Essa ponderação não pode ser absoluta. Deve partir do caso concreto, cotejando-se qual dos princípios em tensão possui, na espécie, o maior peso. Assim é que a ponderação dos princípios não se faz hierarquicamente para o futuro, mais decorre da analise feita no caso concreto. Em uma outra hipótese, em que haja colisão dos mesmos princípios, todavia, a decisão de peso pode se dar em sentido oposto, mantendo-se, contudo, os princípios no ordenamento jurídico. Não há, pois, tarifação estática entre os princípios, os princípiosque informam as regras devem ser avivados, fazendo-se, posteriormente, a ponderação dos respectivos pesos diante do caso concreto. A colisão, portanto, se dará na frequência dos princípios, mediante o processo de busca, no plano destes, do pedigree das regras, com a possibilidade plena de resolução da antinomia.

Mello ${ }^{11}$ leciona quanto a violação dos princípios, entende ele que:

Violar um princípio é muito mais grave do que transgredir uma norma. A desatenção ao princípio implica ofensa não apenas a um especifico mandamento obrigatório, mas a todo o sistema de comandos. Ë a mais grave forma de ilegalidade ou inconstitucionalidade, conforme o escalão do princípio atingido, porque representa insurgência contra o sistema, subversão de seus valores fundamentais.

\footnotetext{
10 MORAIS DA ROSA, Alexandre. Princípios Ambientais, direitos fundamentais, propriedades e abuso de direito: por uma leitura a partir do garantismo jurídico (Ferrajoli). In FREITAS, Vladimir Passos de (Coord.). Direito ambiental em evolução - n³. 1a. Ed. Curitiba: Juruá, 2007. p.47.

${ }^{11}$ MELLO, Celso Antônio Bandeira de. Elementos de Direito Administrativo. São Paulo: Revista dos Tribunais, 1980 , p. 229-230.
} 
SOUZA, Greyce Kelly Antunes de. A importância do Princípio da Informação: a necessidade de consciência social acerca dos problemas ambientais para maior proteção ambiental. Revista Eletrônica Direito e Política, Programa de Pós-Graduação Stricto Sensu em Ciência Jurídica da UNIVALI, Itajaí, v.10, n.2, $1^{\circ}$ quadrimestre de 2015. Disponível em: www.univali.br/direitoepolitica - ISSN 1980-7791.

Uma vez elucidado a importância dos princípios, passa-se a analise do Principio da Informação e seus efeitos no contexto ambiental.

\section{PRINCÍPIO DA INFORMAÇÃO}

\subsection{Conceito}

Tratar-se-á do princípio da Informação o qual faz parte do enfoque central da presente pesquisa.

Incialmente, vale se deter brevemente ao vocábulo informação.

Segundo Paulo Affonso Leme Machado12, "A informação é um registro do que existe ou do que está em processo de existir. Antes de pensar nos fins da informação, ela é aqui entendida como "dados acerca de alguém ou de algo".

Ainda afirma Machado ${ }^{13}$

Ao se conceituar "informação", não se aborda a quem ela pertence, onde ela se encontra e nem qual a finalidade de sua existência, mas um primeiro aspecto: os informes são identificados e organizados, isto é, não ficam dispersos ou de difícil manuseio.

Nesse sentido o autor destaque que:

A transmissão de informação é o motor de toda a sociedade animal, porque toda a vida social requer comunicação, não só para manter o grupo social, como para que este e a própria espécie sobrevivam, acumulando e transmitindo a seus congêneres e crias, de uma parte, sinais de alarmes frente aos perigos e, de outra, conhecimento de adaptação ao meio sem os quais toda a espécie acabaria desaparecendo. ${ }^{14}$

\footnotetext{
12 MACHADO, Paulo Affonso Leme. Direito à informação e meioambiente. São Paulo: Malheiros, 2006. p. 25-26.

13 MACHADO, Paulo Affonso Leme. Direito à informação e meio ambiente. São Paulo: Malheiros, 2006. p. 26

14 MACHADO, Paulo Affonso Leme. Direito à informação e meio ambiente. São Paulo: Malheiros, 2006. p. 52
} 
SOUZA, Greyce Kelly Antunes de. A importância do Princípio da Informação: a necessidade de consciência social acerca dos problemas ambientais para maior proteção ambiental. Revista Eletrônica Direito e Política, Programa de Pós-Graduação Stricto Sensu em Ciência Jurídica da UNIVALI, Itajaí, v.10, n.2, $1^{\circ}$ quadrimestre de 2015. Disponível em: www.univali.br/direitoepolitica - ISSN 1980-7791.

Portanto, o direito à informação protege cada pessoa, tendo em vista que é a base sobre a qual se tomara decisões que influenciarão nos interesses e necessidade de cada um. ${ }^{15}$

\subsection{Breve previsão histórica do Princípio da Informação no contexto ambiental}

Tratando de direito à informação em caráter ambiental, Mateo ${ }^{16}$ dispõe que o mesmo decorreu de uma série de declarações internacionais, entre as quais a Conferência de Estocolmo em 1972, cujos princípios 19 e 20 recomendam aos Estados que divulguem informações atualizadas concernentes à melhoria do ambiente, também ressaltou a necessidade fomentar a pesquisa e o desenvolvimento cientifico, o livre intercâmbio de experiências, de forma a garantir o acesso dos países em desenvolvimento às chamadas tecnologias limpas.

A Conferência de Estocolmo também estabeleceu, principalmente por intermédio dos meios de comunicação, a importância da divulgação de informações como base para fundamentar a opinião pública consciente de suas responsabilidades ambientais e sociais. ${ }^{17}$

O direito a informação decorreu de dois importantes pronunciamentos: A Declaração dos Direitos de Virginia de 1776 e a Declaração Universal dos Direitos do Homem e do Cidadão de 1789, que resultaram no aparecimento das ditas liberdades públicas e os instrumentos de controle do Estado, como a liberdade de imprensa, a liberdade de expressão e o fim da censura. ${ }^{18}$

\footnotetext{
15 MACHADO, Paulo Affonso Leme. Direito à informação e meio ambiente. São Paulo: Malheiros, 2006. p. 52

16 MATEO, Ramón Martín. Manual de derecho ambiental. p. 121-123.

17 MATEO, Ramón Martín. Manual de derecho ambiental. p. 121-123.

18 GRAF. Ana Cláudia Bento. O direito à informação ambiental. In: FREITAS, Vladimir Passos de (org.). Direito ambiental em evolução - n. ${ }^{\circ}$ 1. 2a. ed. Curitiba: Juruá, 2002. p. 15-16.
} 
SOUZA, Greyce Kelly Antunes de. A importância do Princípio da Informação: a necessidade de consciência social acerca dos problemas ambientais para maior proteção ambiental. Revista Eletrônica Direito e Política, Programa de Pós-Graduação Stricto Sensu em Ciência Jurídica da UNIVALI, Itajaí, v.10, n.2, $1^{\circ}$ quadrimestre de 2015. Disponível em: www.univali.br/direitoepolitica - ISSN 1980-7791.

No mesmo sentido, a $1^{\circ}$ Conferência Européia sobre o Meio Ambiente e saúde, realizada em Frankfurt em 1989, lança como sugestão à Comunidade Econômica Européia uma Carta Européia do meio Ambiente e da Saúde expondo que, em resumo, cada pessoa tem o direito de beneficiar-se de um meio ambiente, permitindo a realização do nível mais elevado possível de saúde e de bem-estar, de ser informado e consultado sobre os planos e decisões e atividades suscetíveis de afetar ao mesmo tempo o meio ambiente e a saúde, de participar do processo de tomada das decisões. ${ }^{19}$

Por conseguinte, o princípio 10 da Declaração do Rio de Janeiro ${ }^{20}$, proclama o direito à informação de todos os cidadãos interessados como sendo a melhor maneira de lidar com as questões ambientais. ${ }^{21}$

A ideia de ser informado somente ganhou força no século $X X$, tendo por fundamento a premissa da informação como um direito subjetivo de alcance coletivo, valido diante do Estado e dos meios de comunicação que se ocupam da atividade informativa. ${ }^{22}$

A Convenção sobre o acesso à informação, Convenção de Aarhus, em vigor desde 30 de outubro de 2001 na Comunidade Europeia, torna possível aos cidadãos obter informações sobre o meio ambiente, mediante solicitação ao Poder Público, ressalvados os dados de caráter confidencial. ${ }^{23}$

Neste contexto, a Agenda 21 brasileira, declara que um sistema de informação é necessário à implementação da modernização do Estado e ao novo modelo para o desenvolvimento sustentável, tendo como de gestão ambiental a instituição de

19 GRAF. Ana Cláudia Bento. O direito à informação ambiental. In: FREITAS, Vladimir Passos de (org.). Direito ambiental em evolução - n. ${ }^{\circ}$ 1. 2a. ed. Curitiba: Juruá, 2002. p. 17-19

20 BRASIL, Ministério do Meio Ambiente. Declaração do Rio sobre o Meio Ambiente e Desenvolvimento. http://www.mma.gov.br/port/sdi/ea/documento/convs/decl_rio92.pdf. Acesso em: 17 de abril de 2015.

21 PRIEUR, Michel. Droit de I' environnement. 4. ed. Paris: Dalloz, 2001. p.99.

22 LIZARRAGA, José Antonio Razquin; ESPINOSA, ÁNGEL Ruiz de Apodaca. Información, participación y justicia em matéria de médio ambiente: comentário sistemático a laLey 27/2006, de 18 de julio. p. 167.

23 LEMOS, Patrícia FagaInglesias. Resíduos sólidos e responsabilidade civil pósconsumo.p.50. 
SOUZA, Greyce Kelly Antunes de. A importância do Princípio da Informação: a necessidade de consciência social acerca dos problemas ambientais para maior proteção ambiental. Revista Eletrônica Direito e Política, Programa de Pós-Graduação Stricto Sensu em Ciência Jurídica da UNIVALI, Itajaí, v.10, n.2, $1^{\circ}$ quadrimestre de 2015. Disponível em: www.univali.br/direitoepolitica - ISSN 1980-7791.

um Sistema de informação com a definição de indicadores de desenvolvimento sustentável para o gerenciamento das políticas públicas. ${ }^{24}$

E indo mais além, percebe-se que o princípio também ganhou forma de artigo 225, $\S 1^{\circ}$, V da Constituição Federal ${ }^{25}$, onde diz que incube ao poder público promover a educação ambiental em todos os níveis de ensino e a conscientização pública para a preservação do meio ambiente. Neste mesmo artigo também consagrou o meio ambiente como bem se uso comum ao povo e essencial à sadia qualidade de vida, a onde deve ser protegido e preservado para às presentes e futuras gerações.

Assim a Carta Constitucional institui a democracia do acesso aos recursos ambientais e a obrigação de todos de zelar pela qualidade do meio ambiente, em respeito ao direito universal ao ambiente ecologicamente equilibrado.

Ainda, a luz da Constituição Federal ${ }^{26}$ no seu artigo 220 explica o direito que a coletividade detém não só à informação como de ser informada. Este é um dos pilares do Direito difuso e coletivo. Cessam, entretanto, quaisquer dúvida sobre a importância do tema.

Nesse sentido a norma brasileira constante da Lei de Política Nacional do Meio Ambiente diz: "Art. 9०. São instrumentos da Politica da Politica Nacional do Meio Ambiente: (...) XI - a garantia da prestação de informações relativas ao meio ambiente, obrigando-se o Poder Público a produzi-las, quando inexistentes". ${ }^{27}$

Ressalta Padilha ${ }^{28}$ que:

A Lei $n^{\circ}$. 10.650/2003 29 , em que complementa à Lei de Politica Nacional do Meio Ambiente ${ }^{30}$, dispõe sobre o acesso

\footnotetext{
${ }^{24}$ PADILHA, Norma Sueli. Fundamentos constitucionais do direito ambiental brasileiro. $p$. 263

${ }^{25}$ BRASIL. Constituição da República Federativa do Brasil, de 05 de outubro de 1988.

${ }^{26}$ BRASIL. Constituição da República Federativa do Brasil, de 05 de outubro de 1988.

${ }^{27}$ BRASIL. Lei da Política Nacional do Meio Ambiente. Lei n. 6.938 de 31 de agosto de 1981.

28 PADILHA, Norma Sueli. Fundamentos constitucionais do direito ambiental brasileiro. p. 263

${ }^{29}$ BRASIL. Lei n. 10.650, de 16 de abril de 2013.
} 
SOUZA, Greyce Kelly Antunes de. A importância do Princípio da Informação: a necessidade de consciência social acerca dos problemas ambientais para maior proteção ambiental. Revista Eletrônica Direito e Política, Programa de Pós-Graduação Stricto Sensu em Ciência Jurídica da UNIVALI, Itajaí, v.10, n.2, $1^{\circ}$ quadrimestre de 2015. Disponível em: www.univali.br/direitoepolitica - ISSN 1980-7791.

público aos dados e informações ambientais existentes nos órgãos integrantes do SISNAMA, determinando aos mesmos acesso público aos documentos e processos administrativos que tratem de matéria ambiental, além do fornecimento de todas as informações ambientais que detenham.

Desta forma o direito à informação foi ganhando espaço no direito ambiental, e o princípio sendo cada vez mais aplicado. Para tanto é preciso que as pessoas tenham conhecimento do ambiente em que vivem, e conhecimento sobre o que contribuir para sua conservação, como será tratado no próximo tópico.

\section{PRINCÍPIO DA INFORMAÇÃO E SUA FUNÇÃO AO MEIO AMBIENTE}

O acesso à informação ambiental estabelece não só em razão da crescente sensibilidade social no que se refere ao ambiente como também pelo seu desenvolvimento normativo. ${ }^{31}$

Quanto maior for o conhecimento acerca das características, da fragilidade, potencialidade, vulnerabilidade e singularidade do conjunto de bens ambientais existentes, maior será o devido cuidado de proteção e, consequentemente, a preservação dos recursos naturais. ${ }^{32}$

Lizarraga e Espinosa ${ }^{33}$ tratam sobre o direito à informação:

Na área ambiental, o direito à informação tem especial relevância, dada a natureza coletiva do direito a um meio ambiental adequado e a responsabilidade comum de todos na proteção do mesmo, assim como a fragilidade e difícil reparação do meio ambiente. O direito à informação ambiental implica efeitos positivos claros, como os seguintes: 1) Forma a consciência social e educa a coletividade acerca dos problemas ambientais; 2) Propicia a

\footnotetext{
${ }^{30}$ BRASIL. Lei da Política Nacional do Meio Ambiente. Lei nº. 6.938 de 31 de agosto de 1981.

31 LIZARRAGA, José Antonio Razquin; ESPINOSA, ÁNGEL Ruiz de Apodaca. Información, participación y justicia em matéria de médio ambiente: comentário sistemático a laLey 27/2006, de 18 de julio. p. 181.

32 ZSOGON, Silvia Jaquenod de. Derecho ambiental: información; investigación. p. 40.

33 LIZARRAGA, José Antonio Razquin; ESPINOSA, ÁNGEL Ruiz de Apodaca. Información, participación y justicia em matéria de médio ambiente: comentário sistemático a laLey 27/2006, de 18 de julio. p. 168.
} 
SOUZA, Greyce Kelly Antunes de. A importância do Princípio da Informação: a necessidade de consciência social acerca dos problemas ambientais para maior proteção ambiental. Revista Eletrônica Direito e Política, Programa de Pós-Graduação Stricto Sensu em Ciência Jurídica da UNIVALI, Itajaí, v.10, n.2, $1^{\circ}$ quadrimestre de 2015. Disponível em: www.univali.br/direitoepolitica - ISSN 1980-7791.

participação efetiva dos cidadãos nas questões ambientais; 3) Funciona como um instrumento de controle democrático que visa assegurar o cumprimento das normas ambientais.

Ainda nos dizeres de Lizarraga e Espinosa ${ }^{34}$, o acesso à informação ambiental possui duas premissas básicas: a conscientização dos cidadãos acerca das questões ambientais de interesse geral, com vistas à melhoria da preservação ambiental, e a consequente participação pública nas tomadas de decisão que afetam a comunidade como um todo.

Para Prieur ${ }^{35}$ a proteção ambiental só terá sucesso quando houver disponibilidade de informação à coletividade no que diz respeito ao meio ambiente e aos empreendimentos que possam prejudica-los, podendo ser referida informação procedente de dados disponibilizados pelo Poder Público de forma espontânea ou quando solicitados pela comunidade. Só então, a informação prestada possibilitará a participação da coletividade.

E ainda, para que ocorra a participação ambiental mediante a informação, por consequência também a educação ambiental, é requisito indispensável que tal informação venha em condições adequadas, para que o receptor desta possa selecionar e compreender os dados. Desta forma será possível a almejada mudança de atitudes perante o tratamento dos recursos naturais. ${ }^{36}$

Conforme Machado, a informação ambiental é um interesse difuso, que não necessita de comprovação de interesse pessoal do informado, bastando a constatação de esclarecimentos relativos aos fins e razões do pedido. De modo que as autoridades públicas não são proprietárias de tal informação, e sim gestoras desses dados em nome da coletividade. ${ }^{37}$

A informação é o início da conscientização do povo. Ela deve ser, na medida do possível, irrestrita e abrangente. Somente quando houver entendimento e

34 LIZARRAGA, José Antonio Razquin; ESPINOSA, ÁNGEL Ruiz de Apodaca. Información, participación y justicia em matéria de médio ambiente: comentário sistemático a laLey 27/2006, de 18 de julio. p. 167.

35 PRIEUR, Michel. Droit de I' environnement. p. 99.

${ }^{36}$ ZSOGON, Silvia Jaquenod de. Derecho ambiental: información; investigación. p.42.

${ }^{37}$ MACHADO, Paulo Affonso Leme. Direito à informação e meio ambiente. p. 95. 
SOUZA, Greyce Kelly Antunes de. A importância do Princípio da Informação: a necessidade de consciência social acerca dos problemas ambientais para maior proteção ambiental. Revista Eletrônica Direito e Política, Programa de Pós-Graduação Stricto Sensu em Ciência Jurídica da UNIVALI, Itajaí, v.10, n.2, $1^{\circ}$ quadrimestre de 2015. Disponível em: www.univali.br/direitoepolitica - ISSN 1980-7791.

clareza da necessidade de um ambiente saudável e de como conservá-lo, haverá uma mobilização adequada por parte da sociedade, sujeita às consequências da sua utilização.

Assim, após decorrer sobre o Princípio da Informação no contexto ambiental, claramente nota-se a importância do direito à informação quanto ao meio ambiente e seus efeitos positivos, uma vez que quanto maior for o conhecimento acerca das características, das fragilidades, e singularidades do conjunto de bens ambientais existentes, maior será a respectiva da proteção ambiental e, por consequência, da preservação dos recursos naturais.

Esse acesso pleno a informações ambientais proporcionam uma avaliação da grandeza e a importância dos bens naturais disponíveis, ao mesmo tempo que apresenta respostas aos abusos constantes, como forma de assegurar a vida dos seres e manter o equilíbrio do meio ambiente, impedindo, assim, um efeito devastador e irreversível para a sobrevivência do homem e dos demais animais do planeta.

\section{CONSIDERAÇÕES FINAIS}

O ser humano depende de comunicação como forma de desenvolvimento e perpetuamento da vida. As pessoas, por meio da comunicação, participam das transformações da sociedade que estão inseridas e, desta forma, traçam seu próprio destino. $\mathrm{E}$ se a comunicação compromete a área ambiental, a importância dessa ponderação aumenta de seriedade.

Observou-se que para a sociedade ter consciência do que está acontecendo com o meio ambiente, e poder tomar posição ou se pronunciar a respeito da matéria é de total necessidade a informação fornecida pelo Poder Público, empresas privadas ou entidade responsável.

No Brasil, a Constituição Federal trouxe avanços significativos no que tange à informação sobre a matéria ambiental, visto sua previsão legal. Porém ainda 
SOUZA, Greyce Kelly Antunes de. A importância do Princípio da Informação: a necessidade de consciência social acerca dos problemas ambientais para maior proteção ambiental. Revista Eletrônica Direito e Política, Programa de Pós-Graduação Stricto Sensu em Ciência Jurídica da UNIVALI, Itajaí, v.10, n.2, $1^{\circ}$ quadrimestre de 2015. Disponível em: www.univali.br/direitoepolitica - ISSN 1980-7791.

temos um longo caminho pela frente para atingir a plena efetivação do acesso às informações e educação ambiental.

A Política Nacional do Meio Ambiental e a Lei de Acesso à Informação - Lei $10.650 / 2003$ são marcos importantes na evolução do direito à informação ambiental e traduzem as investidas estatais na busca de uma consciência ambiental coletiva, a fim de efetivas exercício da democracia e participação dos cidadãos nessas questões que envolvem direito de todos.

Por tanto é com base nessa divulgação de informações que irá fundamentar a opinião pública consciente. E se faz necessária que prestada de forma mais completa possível e de forma continuada a fim de conscientizar a população interessa de suas responsabilidades ambientais e sociais, fazendo com que haja a participação nas tomadas de decisões e no uso correto dos recursos naturais.

Ou seja, quanto maior for o conhecimento acerca das características, da fragilidade, potencialidade, vulnerabilidade e singularidade do conjunto de bens ambientais existentes, maior será o devido cuidado de proteção e, consequentemente, a preservação dos recursos naturais.

Desta forma, será possível a almejada mudança de atitudes perante o tratamento dos recursos naturais.

Resta claro, a informação e a educação ambiental, se mostra de extrema necessidade para que a sociedade evite maiores dados ao meio ambiente e aos recursos naturais, favorecendo o entendimento acerca de determinados fenômenos, elementos e processos naturais, bem como protegendo as pessoas e o meio ambiente de eventuais riscos futuros.

Portanto, acredita-se que o acesso à informação ambiental assegura a formação de uma consciência pública, pois se entende que o mesmo contribui com a participação popular consciente e efetiva, tanto no que tange à fiscalização de atuação do Estado, quanto como agente de preservação, o que confirma o pensamento de que o acesso a informação é requisito essencial no processo 
SOUZA, Greyce Kelly Antunes de. A importância do Princípio da Informação: a necessidade de consciência social acerca dos problemas ambientais para maior proteção ambiental. Revista Eletrônica Direito e Política, Programa de Pós-Graduação Stricto Sensu em Ciência Jurídica da UNIVALI, Itajaí, v.10, n.2, $1^{\circ}$ quadrimestre de 2015. Disponível em: www.univali.br/direitoepolitica - ISSN 1980-7791.

participativo favorecendo, portanto, o desenvolvimento sustentável da sociedade.

\section{REFERÊNCIAS BIBLIOGRÁFICAS}

ATALIBA, Geraldo. República e constituição. 2.ed. São Paulo: Malheiros, 2006. BARROSO, Luís Roberto. Interpretação e aplicação da constituição. São Paulo: Saraiva, 1996.

BRASIL. Constituição da República Federativa do Brasil, de 05 de outubro de 1988.

BRASIL. Lei da Política Nacional do Meio Ambiente. Lei $n^{\circ}$. 6.938 de 31 de agosto de 1981.

BRASIL. Lei $\mathbf{n}^{\circ}$. 10.650, de 16 de abril de 2013.

BRASIL. Lei da Política Nacional do Meio Ambiente. Lei $n^{\circ} .6 .938$ de 31 de agosto de 1981.

BRASIL, Ministério do Meio Ambiente. Declaração do Rio sobre o Meio Ambiente e Desenvolvimento. Disponível em: http://www.mma.gov.br/port/sdi/ea/documento/convs/decl_rio92.pdf.

CANOTILHO, J.J. Gomes. Constitucional e teoria da constituição. $7^{\circ}$ ed. Coimbra: Portugual: Almedina, 2003.

GRAF. Ana Cláudia Bento. O direito à informação ambiental. In: FREITAS, Vladimir Passos de (org.). Direito ambiental em evolução - n. ${ }^{\circ} 1.2^{a}$. ed. Curitiba: Juruá, 2002.

GUASTINI, Riccardo. Das fontes às normas. Tradução de Edson Bini. São Paulo: Editora QuartierLatin do Brasil, 2005.

LEMOS, Patrícia FagaInglesias. Resíduos sólidos e responsabilidade civil pós-consumo.

LIZARRAGA, José Antonio Razquin; ESPINOSA, ÁNGEL Ruiz de Apodaca. Información, participación y justicia em matéria de médio ambiente: comentário sistemático a laLey 27/2006, de 18 de julio.

MACHADO, Paulo Affonso Leme. Direito à informação e meio ambiente.

MATEO, Ramón Martín. Manual de derecho ambiental. 
SOUZA, Greyce Kelly Antunes de. A importância do Princípio da Informação: a necessidade de consciência social acerca dos problemas ambientais para maior proteção ambiental. Revista Eletrônica Direito e Política, Programa de Pós-Graduação Stricto Sensu em Ciência Jurídica da UNIVALI, Itajaí, v.10, n.2, $1^{\circ}$ quadrimestre de 2015. Disponível em: www.univali.br/direitoepolitica - ISSN 1980-7791.

MELLO, Celso Antônio Bandeira de. Elementos de Direito Administrativo. São Paulo: Revista dos Tribunais, 1980.

MORAIS DA ROSA, Alexandre. Princípios Ambientais, direitos fundamentais, propriedades e abuso de direito: por uma leitura a partir do garantismo jurídico (Ferrajoli). In FREITAS, Vladimir Passos de (Coord.). Direito ambiental em evolução - n³. 1a. Ed. Curitiba: Juruá, 2007.

PADILHA, Norma Sueli. Fundamentos constitucionais do direito ambiental brasileiro.

PRIEUR, Michel. Droit de I' environnement.

SIRVINSKAS, Luis Paulo. Manual de direito ambiental. 12. Ed. São Paulo: Saraiva, 2014.

ZSOGON, Silvia Jaquenod de. Derecho ambiental: información; investigación.

Submetido em: Março/2015

Aprovado em: Abril/2015 